\title{
BIOMONITOREO GENÉTICO EN TRABAJADORES DEL SERVICIO DE RADIOLOGÍA DEL HOSPITAL NACIONAL POLICIAL LUIS N. SÁENZ
}

\author{
GENETIC BIOMONITORING IN WORKERS OF THE RADIOLOGY SERVICE OF A PERUVIAN NATIONAL HOSPITAL
}

Walter Iván Infantes-Vizcarra1,2,a.

\begin{abstract}
RESUMEN
Objetivo: Evaluar el efecto genotóxico en trabajadores expuestos a rayos $\mathrm{X}$ en el servicio de radiología del Hospital Nacional Luis N. Sáenz PNP. Métodos: Estudio observacional, prospectivo, analítico, utilizando el ensayo cometa como técnica de análisis. La población de estudio fue de 20 trabajadores expuestos a los rayos X y 20 personas sin exposición. Resultados: La media de longitud de migración de ADN dañado

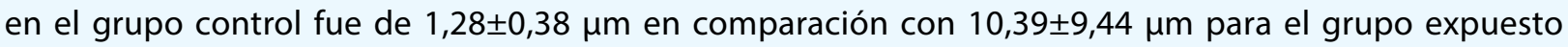
$(p=0,001)$. El daño de ADN se correlacionó significativamente con los años de exposición y dosis recibida pero no con la edad. Conclusión: Los rayos $X$ a dosis bajas consideradas como permisibles pueden causar daño en la integridad del ADN, teniendo correlación con los años de exposición en el personal que trabaja en el servicio de radiología.
\end{abstract}

Palabras clave: Genotoxicidad; Rayos X; Ensayo cometa; Salud laboral (fuente: DeCS BIREME).

\begin{abstract}
Objective: To evaluate the genotoxic effect on workers exposed to X-rays in the radiology service of the Luis N. Sáenz national hospital PNP. Methods: The type of study was observational, prospective, analytical, using the comet assay as an analysis technique. The study population was 20 workers exposed to X-rays and 20 people without exposure. Results: The mean length of migration of damaged DNA in the control group was $1.28 \pm 0.38 \mu \mathrm{m}$ compared to $10.39 \pm 9,44 \mu \mathrm{m}$ for the exposed group $(p=0,001)$. DNA damage was significantly correlated with years of exposure and dose received $(p<0,05)$ but not with age. Conclusion: $\mathrm{X}$-rays at low permissible doses can cause damage to DNA integrity, correlating with the years of exposure and total dose exposure of personnel working in the radiology service.
\end{abstract}

Key words: Genotoxic; Exposure; X-ray; Comet test; Occupational health (source: MeSH NLM).

\section{INTRODUCCIÓN}

La integridad del material genético se ve comprometida con la exposición a radiación ionizante, dando origen a cambios genéticos como supresiones y ruptura de una o de las dos cadenas del $A D N^{(1)}$. Los efectos biológicos por las radiaciones ionizantes (rayos $\mathrm{X}$ ) varían de acuerdo con el tiempo de exposición e intensidad, y las consecuencias se manifiestan en muchos órganos. La exposición a altas dosis de radiación induce la muerte celular provocando la pérdida de funcionalidad de uno o varios tejidos ${ }^{(2,3)}$. Actualmente, cobran importancia los efectos de las radiaciones ionizantes a dosis bajas y aún más a dosis menores de 20-250mSv/año, límite establecido por los organismos internacionales (IAEA) para la población expuesta laboralmente como el valor por debajo del cual, el riesgo es considerado mínimo pero no inexistente ${ }^{(4,5)}$. Es por ello que se ha visto incrementada la investigación a este respecto in vitro e in vivo, desde el análisis de los mecanismos de toxicidad molecular, genotoxicidad, hasta la búsqueda de herramientas de biomonitoreo genético y biodosimetría que permitan una aproximación al daño y mejor evaluación de

1 Servicio de Radiología, Hospital Nacional PNP "Luis N. Sáenz", Lima-Perú.

${ }^{2}$ Facultad de Ciencais Biológicas, Universidad Ricardo Palma, Lima-Perú.

a Biólogo.

Citar como: Walter Iván Infantes-Vizcarra. Biomonitoreo genético en trabajadores del servicio de radiología del Hospital Nacional Policial Luis N

Sáenz. Rev. Fac. Med. Hum. Enero 20120; 20(1):51-54. DOI 10.25176/RFMH.v20i1.2256

Artículo publicado por la Revista de la Facultad de Medicina Humana de la Universidad Ricardo Palma. Es un artículo de acceso abierto, distribuído bajo los términos de la Licencia Creative Commons: Creative Commons Attribution 4.0 International, CC BY 4.0 (https://creativecommons.org/licenses/by/4.0/), que permite el uso no comercial, distribución y reproducción en cualquier medio, siempre que la obra original sea debidamente citada. Para uso comercial, por favor póngase en contacto con revista.medicina@urp.pe 
riesgo a corto, mediano y largo plazo, permitiendo la implementación de medidas de control ${ }^{6}$. Las rupturas de cadena simple y la formación de sitios lábiles al álcali en el ADN, son parámetros ampliamente utilizados para la detección de genotoxicidad. El ensayo cometa es una prueba muy versátil y adaptable, capaz de dar información sobre los diferentes tipos de daños al ADN presentes en una célula, y también sobre la capacidad celular para reparar los daños ${ }^{(7)}$.

En el Perú, existen pocas estadísticas que hablen de riesgos o accidentes y lesiones laborales, a los que se exponen los profesionales de la radiología ${ }^{(8)}$. La utilidad del estudio genotóxico radica en demostrar y determinar la relación entre el daño genético y la radiación ionizante. Además, permite realizar recomendaciones para prevenir enfermedades $s^{(9,10)}$. El propósito de esta investigación fue determinar el efecto genotóxico de los rayos $X$ en el personal laboralmente expuesto del servicio de radiología del hospital nacional Luis N. Sáenz PNP de Lima en comparación con controles no expuestos de la misma institución.

\section{MÉTODOS}

El tipo de estudio fue observacional, prospectivo, transversal, analítico, realizado durante el periodo de septiembre a octubre del 2013. La población de estudio fue de 40 personas dividida en 2 grupos, el 1er grupo correspondió a 20 trabajadores expuestos a los Rayos $X$ del servicio de radiología del Hospital Nacional PNP Luis N. Sáenz de Lima, con 6 horas de exposición diaria por 5 días a la semana y un tiempo laboral de exposición de 2 años como mínimo y de edad de 20 años a más. El grupo control estuvo conformado por personas del mismo centro de trabajo sin exposición a Rayos X. La participación al estudió fue voluntaria firmando una carta de consentimiento informado para autorizar la toma de muestra de sangre. El estudio fue aprobado por el comité de ética del hospital. Las muestras fueron enviadas al laboratorio de Toxicogenética del Centro Nacional de Salud Ocupacional y Protección del Ambiente para la Salud (CENSOPAS) del Instituto Nacional de Salud (INS) para su procesamiento.

El ensayo cometa se realizó en condiciones alcalinas, de acuerdo al método de Singh et al. (1988) con algunas modificaciones menores ${ }^{(11,12)}$.Las muestras sanguíneas fueron obtenidas por punción venosa con tubos de heparina y la obtención de los linfocitos fue por gradiente de Percoll que se centrifugó a 2200 rpm por 10 minutos. Posteriormente se preparó alícuotas de 25 ul de las muestras de linfocitos que fueron suspendidas en $75 \mu \mathrm{L}$ de agarosa de bajo punto de fusión $(0,5 \%)$ y se añadieron a dos láminas previamente preparadas con agarosa. Posteriormente, estas fueron sumergidas en disolución de lisis $(\mathrm{NaCl} 2,5 \mathrm{~mol} / \mathrm{L}$, EDTA 0,1 mol/L y Tris $0,01 \mathrm{~mol} / \mathrm{L}, 1 \%$ Tritón, $10 \%$ DMSO, pH 10) por 1 $\mathrm{h}$ a $4{ }^{\circ} \mathrm{C}$ y sometidas a 20 min de desenrollamiento en disolución reguladora de electroforesis $(3 \% \mathrm{NaOH} 10$ $\mathrm{mol} / \mathrm{L}, 0,5 \%$ EDTA $0,2 \mathrm{~mol} / \mathrm{L}$, $\mathrm{pH}$ 13). La electroforesis se realizó a $300 \mathrm{~mA}$ y $1,25 \mathrm{~V} / \mathrm{cm}$ durante $20 \mathrm{~min}$, todo en oscuridad. Las láminas fueron lavadas con disolución reguladora de neutralización (Tris $0,4 \mathrm{~mol} / \mathrm{L}, \mathrm{pH} 7,5$ ) y luego las láminas fueron deshidratadas con etanol por 3 minutos. Las preparaciones se tiñeron con bromuro de etidio(11,12). La visualización se realizó utilizando un microscopio de epifluorescencia. La imagen de cada célula se capturo empleando el programa Komet 4. Para cuantificar el daño del ADN, se consideró la distancia de migración de longitud de cola en $\mu \mathrm{m}$, considerando los siguientes niveles: nivel 0 , sin daño (0-5 $\mu \mathrm{m})$; nivel 1, bajo daño $(6-20 \mu \mathrm{m})$; nivel 2 , daño medio $(21-40 \mu \mathrm{m})$; nivel 3, alto daño $(41-80 \mu \mathrm{m})$, y nivel 4 , muy dañado $(>80 \mu \mathrm{m})$ (tabla 1$)^{(12,16,17)}$.

El análisis estadístico se realizó a través del uso del software SPSS v 21.0. Se utilizó la prueba de U de Mann Whitney para el contraste de grupos en el caso de variables cuantitativas; Chi cuadrado para comparación de niveles de daño, Correlación de Spearman para evaluar la asociación entre variables numéricas. Se consideró como estadísticamente significativo un valor de $p<0,05$.

\section{RESULTADOS}

El total de individuos analizados fue de 40 personas. El grupo expuesto estuvo conformado por 5 mujeres y 15 hombres; mientras que el grupo control estuvo conformado por 7 mujeres y 13 hombres. La edad promedio del grupo expuesto fue de 43,2 $\pm 9,31$ años, mientras que la del grupo control fue de $45,5 \pm 5,92$ años. Los valores de la dosis media de la radiación ionizante del grupo expuesto fueron de $0,64 \pm 0,58$ mSv (V.N 20-50 mSv). El tiempo de trabajo del personal expuesto fue de 4 a 30 años con una media de exposición de $12 \pm 8,98$ años.

En la Tabla 1 se resume los valores obtenidos del ensayo cometa, entre el grupo control y expuesto. El estadístico $U$ de Mann Whitney para la comparación de los valores de los 2 grupos mostro una diferencia estadísticamente significativa $(p=0,001)$. La prueba de $X^{2}$ para comparar los niveles de daño entre los grupos también presento un valor significativo $(p=0,01)$. 
Tabla 1. Comparación del daño de ADN por los rayos $X$ entre el grupo expuesto y control.

\begin{tabular}{lcccccc} 
Grupo & $\begin{array}{c}\text { Migracion de ADN } \\
\text { dañado }\end{array}$ & \multicolumn{5}{c}{ Nidel de daño del ADN } \\
Control & $(\mu \mathrm{m})$ & $0(0-5 \mu \mathrm{m})$ & $1(6-20 \mu \mathrm{m})$ & $2(21-40 \mu \mathrm{m})$ & $3(41-80 \mu \mathrm{m})$ & $4(>80 \mu \mathrm{m})$ \\
Expuestos & $1.26 \pm 0.38$ & $1.26 \pm 0.38$ & 0 & 0 & 0 & 0 \\
\hline
\end{tabular}

Test de U Mann White $p=0,001(p<0,05)$.

Test $X 2 p=0,01(p<0,05)$ Nivel daño: $0=$ sin daño, $1=$ bajo daño, $2=$ medio daño, $3=$ alto daño, $4=$ muy dañado Los valores mostrados refieren a la media $\pm D$ D.E. de los grupos estudiados.

En la Tabla 2, se muestran los coeficientes de Spearman para la correlación de edad, año exposición, dosis recibida (mSv) y el daño de ADN. Se encontraron correlaciones positivas estadísticamente significativas $(p<0,05)$ entre los parámetros de año de exposición, dosis recibida y el daño de ADN. No se encontró correlación significativa con la edad $(p>0,05)$.

Tabla 2. Coeficiente de correlación de Spearman entre edad, años de exposición y dosis recibida (mSv).

\begin{tabular}{cccccccc}
\hline & \multicolumn{3}{c}{ Variables de estudio } \\
& \multicolumn{3}{c}{ Edad } & & Años exposición & \multicolumn{2}{c}{$\mathrm{mSv}$} \\
Daño ADN cola & $r$ & $p$ & $r$ & $p$ & $r$ & $p$ \\
\hline & $-0,237$ & 0,141 & 0,720 & 0,003 & 0,218 & 0,001 \\
\hline
\end{tabular}

\section{DISCUSIÓN}

Los datos obtenidos nos indican que la exposición ocupacional en el personal del servicio de radiología presenta un incremento estadísticamente significativo del daño de ADN. El ensayo cometa mostró que el valor medio de migración del daño de ADN en el grupo control solo fue de $1,28 \pm 0,38 \mu \mathrm{m}$ y la expuesta fue de $10,39 \pm 9,44 \mu \mathrm{m}$. Este hallazgo está en concordancia con lo descrito por otros autores de como Baquero et.al. (2004), Muñoz et.al (2008) y Ramírez (2002), en donde las dosis efectivas acumuladas mostraron que la cohorte expuesta presenta valores mayores con relación a la no expuesta, confirmando su exposición a la fuente emisora, es decir al intensificador de imágenes ${ }^{(3,5,8)}$. Los niveles de daño encontrados en el grupo control fue del nivel 0 (sin daño) en relación al grupo expuesto que mostro niveles 1 y 2 (daño bajo y medio) presentando una diferencia estadísticamente significativa. Estos resultados obtenidos se relacionan a los estudio de Guerci y Grillo (2007) donde señalan que las lesiones observadas en células expuestas a radiaciones ionizantes corresponden a daño leve, lo cual podría ser atribuido mayoritariamente a lesiones de cadena simple y daño de bases ${ }^{(15)}$.

El estudio de correlación de Spearman entre la edad y el daño del ADN en el personal expuesto a rayos
$X$ no evidenció una asociación estadísticamente significativa. Estos resultados concuerdan con los estudios de Gadhia et.al. (2004) y Martínez et.al. (2010), que no evidenciaron una relación directa de la edad en los individuos expuestos con la radiación ${ }^{(4,14)}$.

Se encontró una alta correlación entre los años de exposición y el daño de ADN ( $r=0,720 ; p=0,003)$. Es decir, que hay un mayor daño de ADN asociado a un mayor número de años de exposición a la radiación. El grupo expuesto a los rayos $\mathrm{X}$ mostro una media de exposición de 12 $\pm 8,98$ años, presentando un rango de exposición en el trabajo de 4-30 años. Los resultados encontrados se relacionan con los estudios que realizaron por Baquero et.al. (2004) y Díaz-Valecillos et.al. (2004) sobre aberraciones cromosómicas y los años de exposición a Rayos $X$ en el trabajo, estos coincidieron que el aumento de daño genético estuvo entre 1-10 años de exposición. Esto puede interpretarse como un incremento del daño cromosómico al inicio de la exposición ${ }^{(3,13)}$.

La correlación entre dosis recibida de mSv y el daño de ADN también fue significativa, aunque en menor magnitud que el total de años de exposición $(r=0,218$; $\mathrm{p}=0,001$ ). El valor de la dosis media de la radiación ionizante del grupo expuesto fue de $0,64 \pm 0,58 \mathrm{mSv}$, el cual está por debajo de los valores anuales (V.N 20-50 
$m S v)^{(8,19)}$. Estos resultados sugieren, que el ADN, puede ser dañado con valores bajos de exposición a rayos $X$. Los resultados obtenidos son consistentes con los hallazgos de Díaz-Valecillos et.al (2004), Muñoz et. al (2008) y Fuentes Puebla et.al (2015) que concluyeron que la exposición crónica a bajas dosis de radiación ionizante es acumulativa a largo plazo y puede inducir la aparición de alteraciones cromosómicas guardando proporción directa con la cantidad total de radiación absorbida a lo largo del tiempo(3,5,18).

\section{CONCLUSIÓN}

Los rayos $\mathrm{X}$ a bajas dosis consideradas permisibles pueden causar un daño en la integridad del ADN, teniendo una correlación con los años de exposición en el personal que trabaja en el servicio de radiología así como con la dosis total de exposición. Los hallazgos sugieren la utilidad del ensayo cometa como una herramienta útil para evaluar la salud ocupacional y prevenir tempranamente el aparecimiento de patologías.

\section{REFERENCIAS BIBLIOGRÁFICAS}

1. Del Cura J, Pedraza S, Gayete A. RADIOLOGIA ESENCIAL. 4ta Ed. Buenos Aires. Argentina. Editorial. Panamericana. 2010. Vol. 1. p. 1-27. Disponible en: https://www.medicapanamericana.com/Libros/Libro/6361/RadiologiaEsencial-incluye-version-digital.html.

2. Munar Casas CR, Rios Mora YM. Análisis del programa de vigilancia epidemiológica de trabajadores con exposición a radiaciones ionizantes en una IPS de Colombia [Internet] [Salud Ocupacional]. [Colombia]: Universidad del Rosario; 2011 [citado 9 de noviembre de 2019]. Disponible en: https:// repository.urosario.edu.co/handle/10336/2272

3. Baquero Pulido H, Guevara Pardo G, Giraldo Suárez M, Osorio Soto LM Aberraciones cromosómicas en trabajadores expuestos a radiaciones ionizantes. Rev Cienc Salud [Internet]. 2004 [citado 9 de noviembre de 2019];2(1). Disponible en: https://revistas.urosario.edu.co/index.php/ revsalud/article/view/591

4. Gadhia PK, Nehal S, Sweta N, Swati P, Krupa P, Meonis P. Cytogenetic Analysis of Radiotherapeutic and Diagnostic Workers Occupationally Exposed to Radiations: Int J Hum Genet. 2004;4(1):65-9.Disponible en https://doi.org/10.1080/09723757.2004.11885872

5. Muñoz J, López A, Sarmiento I, Herrera C, Sánchez M. Biomonitoreo genético de individuos expuestos a radiaciones ionizantes y su relación con el cáncer. Lab. Genética molecular y Citogenética. UCE 2008; 18 (1): 75-82. Disponible en: https://issuu.com/udlaecuador/docs/librogeneticamolecula

6. Prieto $M$, Moreno $M$, Nava $P$, Zapata. Investigación, mediante técnicas de dosimetría biológica, de los efectos sobre la salud por causa de las radiaciones ionizantes de profesionales de líneas aéreas. Hospital General Gregorio Marañón. [Tesis de Grado]. Universidad Autónoma de Madrid. España. 2006. Disponlibe en: https://www.semaees/wp-content/ uploads/2011/11/Radiaciones-y-L\%C3\%ADneas-A\%C3\%A9reas.pdf

7. Garaj-Vrhovac V, Zeljezic D. Comet assay in the assessment of the human genome damage induced by $\gamma$-radiation in vitro. Radiol Oncol. de marzo de 2004;38(1):43-7. Disponible en : https://www.researchgate. net/publication/288582942 Comet assay in the assessment of the human_genome_damage_induced_by_g-radiation_in_vitro

8. Ramirez A. Tercerización del trabajo y sobreexposición a radiación ionizante en postulantes a services de minería. An Fac Med. 2002;63(4):291 300. Disponible en: http://sisbib.unmsm.edu.pe/BVRevistas/anales/v63 n4/ pdf/tercerizacion_trabajo.pdf

9. Arencibia D, Rosario L., Rodríguez Y. Evaluación del daño basal e inducido en el ADN de linfocitos de tres líneas de ratones, mediante el ensayo cometa alcalino. Biotecnología Aplicada 2011:28 (2): 101-105. Disponible en: https:// www.medigraphic.com/cgi-bin/new/resumen.cgi?IDARTICULO=36410
Agradecimientos: Al MSc. Blgo. Mauricio Gonzales Molfino por su colaboración y sugerencias. Al Dr. Víctor Manuel García Salazar por permitirme realizar el trabajo en el servicio de radiología del hospital Policial. Al Mg. Jaime Rosales, encargado del laboratorio de genética de CENSOPAS, por su apoyo desinteresado.

Contribuciones de autoría: El autor se encargó de la concepción, análisis de datos y elaboración del manuscrito, asumiendo la responsabilidad por su contenido.

Financiamiento: Autofinanciado.

Conflicto de interés: El autor no declara conflictos de interés.

Recibido: 10 de octubre del 2019

Aprobado: 10 de noviembre del 2019

Correspondencia: Walter Iván Infantes Vizcarra.

Dirección: Laboratorio de Biotecnología animal. Facultad de Ciencias Biológicas. Universidad Ricardo Palma. Av. Alfredo Benavides 5440, Santiago de Surco, Lima-Perú.

Teléfono: (01) 708-0000

Correo:ivan.infantes.vizcarra@gmail.com
10. Collins AR., Oscoz A., Brunborg G, Gaivão I, Giovannelli L, Kruszewski $M$, et al. The comet assay: topical issues. Mutagénesis. 2008; 23(3):51-143. Disponible en: https://www.ncbi.nlm.nih.gov/pubmed/18283046

11. Singh NP, McCoy MT, Tice RR, Schneider EL. A simple technique for quantitation of low levels of DNA damage in individual cells. Exp Cell Res. marzo de 1988;175(1):184-91. Disponible en: https://www.ncbi.nlm.nih. gov/pubmed/3345800

12. Tice RR, Agurell $E$, Anderson D, Burlinson B, Hartmann A, Kobayashi $H_{\text {, }}$ et al. Single cell gel/comet assay: guidelines for in vitro and in vivo genetic toxicology testing. Environ Mol Mutagen. 2000;35(3):206-21. Disponible en: https://www.ncbi.nlm.nih.gov/pubmed/10737956

13. Díaz-Valecillos M, Fernández J, Rojas A, Valecillos J, Cañizales J. Alteraciones cromosómicas en trabajadores expuestos a radiaciones ionizantes. Invest. clín [Internet]. 2004 Sep [citado 2019 Nov 09] : 45( 3 ): 197-211. Disponible en: http://ve.scielo.org/scielo.php?script=sci arttext\&pid=S0535-51332004000300002\&lng=es.

14. Martínez A, Coleman M, Romero-Talamás CA, Frias S. An assessment of immediate DNA damage to occupationally exposed workers to low dose ionizing radiation by using the comet assay. Rev Invest Clin. 2010; 62 (1):23 30. Disponible en: https://www.ncbi.nlm.nih.gov/pubmed/20415056

15. Güerci A., Grillo C. Evaluación del efecto genotóxico por exposición crónica a dosis bajas de radiación ionizante a través de un modelo in vitro. Revista Radiobiología 2007; 7: 166 - 173. Disponible en: https://pdfs. semanticscholar.org/a237/93f92621da78242c457ffb5be3fb8f6b72c3.pdf

16. Güerci A, Zúñiga L, Marcos R. El Valor Predictivo del Ensayo Cometa en la Evaluación de la Radiosensibilidad Individual en Sangre Periférica. Theoria, 2006; 15(2): 41-52. Disponible en: https://www.redalyc.org/ pdf/299/29915205.pd

17. Ravi K, Santosh M, Ajay K. Assessment of DNA Damage by Comet Assay in Lymphocytes of Workers Occupationally Exposed to Petroleum fumes. International Journal of Genetics 2010; 2 (1): 18-22. DOI: 10.9735/09752862.2.1.18-22 Disponible en: https://bioinfopublication.org/files/ articles/2_1_3_IJG.pdf

18. Fuentes Puebla L, Felipe Torres S, Valencia Fernández V. Efectos biológicos de los Rayo-X en la práctica de Estomatología. Rev haban cienc méd [Internet]. 2015 Jun [citado 2019 Nov 09]; 14( 3 ): 337-347. Disponible en: http://scielo.sld.cu/scielo.php?script=sci_arttext\&pid=S1729519X2015000300011\&lng=es.

19. Montoya M. La Ley $\mathrm{N}^{\circ} 28028$ y su aporte trascendental para mejorar la seguridad radiológica y física en el Perú. 2014. Disponible en : https://alicia.concytec.gob.pe/vufind/Record/IPEN b77cbc881e20f5b2e13cc2bc21b91b62 